\title{
EVALUATING INITIAL BUILDING DESIGNS CONSIDERING POSSIBLE FUTURE CHANGES: THE EXAMPLE OF THE NEW PET CENTRE OF THE UNIVERSITY HOSPITAL OF ZURICH
}

\author{
M. Esders ${ }^{\text {I }}$ B. T. Adey ${ }^{2}$ and C. Martani ${ }^{2 *}$ \\ ${ }^{1}$ Pom+ Consulting AG. Technoparkstrasse 1,8005 Zürich, Switzerland \\ ${ }^{2}$ Institute of Construction and Infrastructure Management, ETH. Stefano-Franscini-Platz 5, 8093 Zurich, Switzerland \\ * Corresponding author
}

\begin{abstract}
Building managers aim to ensure that their buildings function as required over a specified period of time. The ability of a building to provide an adequate level of service might change over time due to changes in the level of service required (e.g. demand). The common practice in building management is to plan maintenance and changes without taking into consideration future uncertainty. To overcome the limitation of this approach, recent research has resulted in a process that enables the evaluation of multiple possible initial building designs taking into consideration uncertain future demand. This process has recently been used by (Esders, 2017) to determine the best initial design for the new PET centre of the university hospital of Zurich, considering possible variations in the number of patients and decision flexibility. This has shown that a flexible building is the best initial design, when coupled with a decision flexibility, to maximize the net benefits. As decision flexibility is not always a privilege that building managers are given, in this paper the expected net benefit is estimated for the flexible initial design of the new PET centre of the university hospital of Zurich, using the traditional method, i.e. assuming that the building manager decides at present when and how to plan changes in future. The results are then compared to those obtained with the real option method, and conclusions are drawn on the potentials and limitations of considering decision flexibility when managing this building. Finally, suggestions are made for further research directions.
\end{abstract}

\section{Introduction}

Building managers aim to ensure that their buildings function as required over a specified period of time. The ability of a building to provide an adequate level of service over time changes due to decreases in its ability (e.g. due to deterioration) to provide a specified level of service and due to changes in the level of service required (e.g. demand). The common practice in building management is to plan maintenance and changes, while often not taking explicitly into consideration uncertain future demand. Although neglecting uncertain future demand reduces modelling complexity, it leads to the development of intervention plans that are rarely optimal. Recent research ((Esders, Della Morte and Adey, 2015), (Esders, Adey and Lethanh, 2016)) has resulted in a process that enables the evaluation of multiple possible initial building designs, taking into consideration this uncertain future demand, as well as the ability of building managers to postpone their decision about which changes should be made in the future when better information will be available, i.e. using the real option method (ROM).

This process is particularly useful in situations where irrevocable decisions have to be taken ahead of time and the long-term impact of the uncertainty on the services provided in the hospital has to be considered. One of these situations is certainly the construction of new hospital centres, where the building has to be adequately dimensioned for the patients demand, which is highly uncertain in the long term. In (Esders, 2017), a real option methodology has been proposed to define the optimal initial design for the new positron emission tomography (PET) centre of the university hospital of Zurich. This was done considering that the initial design affects the possibilities and cost of future changes, and that the number and type of patients to be treated is highly uncertain. Indeed, in the current PET centre, circa 4'700 patients are treated yearly. This number, however, can change over time as a consequence of both demographic and technological evolutions (i.e. future models of scanners may, additionally, be able to screen for Alzheimers). For this application, the patients demand was simulated over 40 years with binomial trees on three initial designs: (i) Basic, where only the immediate patients demand is accommodated; (ii) Robust, where the maximum expected future patients demand is accommodated; and (iii) Flexible, where only the immediate patients demand is accommodated, but leaving the possibility to the building manager to expand the service in future, if the need arises. Among the three alternatives, the flexible initial design was identified has the optimal solution, i.e. the one that guarantees the highest net 
benefit over the investigated period, given the uncertainty modelled and the decision flexibility.

In many real world situations, though, decision flexibility, i.e. the possibility to trigger a change whenever it is more convenient, is not a privilege that building managers are given. This is for example the case when long-term budget allocation plans are required to make sure that appropriate financial resources are available at due time for the interventions. In these situations, a flexible initial design can still be used to postpone part of the investment, but the decision on when to trigger an intervention has to be decided ahead of time using a traditional method (TM).

In the present article, the expected net benefit is estimated for the flexible initial design of the new PET centre of the university hospital of Zurich, using the TM, i.e. assuming that the infrastructure manager decides at present when and how to plan a change in future. This is trust to simulate the real world situation in which building managers have to do long-term finance planning to secure the budget for interventions. The results are then compared to these obtained using the ROM, in (Esders, 2017), to investigate the advantage of using the ROM in the real world example considered.

\section{Background}

The potential benefit of building flexible infrastructure in situations of uncertain future demand has been studied. Some of the most relevant examples are shown in Table 1, along with the possible future changes considered in each investigation, as well as the simulation method used, and whether the decision on triggering has been considered as flexible or fixed, i.e. predefined to prepare resource allocation.

Table 1 Examples of research on the impact of future changes on infrastructure

\begin{tabular}{|c|c|c|c|c|}
\hline Infrastructure & Source & Future changes considered & Simulation method & $\begin{array}{l}\text { Decision on } \\
\text { triggering }\end{array}$ \\
\hline \multirow[t]{3}{*}{ Hospitals and clinics } & (de Neufville, Lee & Changes in demographics, changes in & \multirow[t]{2}{*}{ Monte Carlo } & \multirow[t]{2}{*}{ Flexible } \\
\hline & and Scholtes, & $\begin{array}{l}\text { patterns, causes and effects of health } \\
\text { and disease, changes in medical } \\
\text { technology }\end{array}$ & & \\
\hline & (Esders, 2017) & $\begin{array}{l}\text { Changes in demographics and } \\
\text { treatment technologies }\end{array}$ & Binomial trees & Flexible \\
\hline $\begin{array}{l}\text { Heating and cooling } \\
\text { systems in } \text { office } \\
\text { buildings }\end{array}$ & $\begin{array}{l}\text { (Martani et al., } \\
2015,2016)\end{array}$ & $\begin{array}{l}\text { The prices of gas and electricity, } \\
\text { heating and cooling loadings and } \\
\text { performances of the systems }\end{array}$ & $\begin{array}{l}\text { Monte Carlo and } \\
\text { Latin Hypercube } \\
\text { Monte Carlo }\end{array}$ & Flexible \\
\hline $\begin{array}{l}\text { Office } \quad \text { buildings' } \\
\text { façades }\end{array}$ & $\begin{array}{l}\text { (Esders, Adey and } \\
\text { Lethanh, 2016) }\end{array}$ & Operating costs & Binomial trees & Flexible \\
\hline General buildings & (Menassa, 2011) & $\begin{array}{l}\text { Changes in performance of materials } \\
\text { and components }\end{array}$ & Binomial trees & Flexible \\
\hline $\begin{array}{l}\text { Space sharing in } \\
\text { general buildings space }\end{array}$ & $\begin{array}{l}\text { (Fawcett and } \\
\text { Chadwick, 2007; } \\
\text { Fawcett and } \\
\text { Rigby, 2009) }\end{array}$ & Demand of working space & $\begin{array}{l}\text { Agent-based } \\
\text { simulation model }\end{array}$ & Flexible \\
\hline $\begin{array}{l}\text { Layout of general } \\
\text { buildings' ground floor }\end{array}$ & $\begin{array}{l}\text { (Ellingham and } \\
\text { Fawcett, 2007) }\end{array}$ & Commercial rents & Binomial trees & Flexible \\
\hline $\begin{array}{l}\text { Vertical expansion of } \\
\text { office buildings }\end{array}$ & $\begin{array}{l}\text { (Guma A. and de } \\
\text { Neufville, 2008) }\end{array}$ & $\begin{array}{l}\text { Future cash flows (rents), and demand } \\
\text { for office space }\end{array}$ & Monte Carlo & Flexible \\
\hline $\begin{array}{l}\text { Ground floor ceilings in } \\
\text { general buildings }\end{array}$ & $\begin{array}{l}\text { (Martani, } \\
\text { Cattarinussi and } \\
\text { Adey, 2018) }\end{array}$ & Use change rate & Monte Carlo & Flexible \\
\hline
\end{tabular}

It can be noticed from Table 1 that in all 11 examples the decision on triggering a change has been considered to be flexible. This is not a surprising choice as the focus of all these works was to investigate the potential of a flexible design. This has always led to assume the situation when the value of a flexible design could be more clearly observed, i.e. assuming an optimal triggering time. There is, however, a clear lack of investigation with reference to the impact of flexible design under fix decisions on the time of triggering the changes. With reference to the simulation method, instead, in the majority of examples, researchers have used the Monte Carlo method to simulate the variable behaviour $(5 / 11)$ over time, a smaller portion have used binomial trees (4/11) and a few have used other simulation methods (2/11). Binomial trees were used when the problems had variables whose values were expected to change relatively suddenly, such as the number of patients 
in a hospital after a new treatment is introduced. Since the example used in this paper consists of a variable that changes slowly over time and one that changes suddenly over time, binomial trees were used.

\section{Real world example}

Based on the work of (Esders, 2017), in this section the situation, the model to evaluate the service and the method to estimate the net benefit using the ROM are reported.

\subsection{Situation}

The real world example to be investigated is the new PET centre of the university hospital of Zurich that is to be constructed to house the clinic of nuclear medicine. The new PET centre will replace the current one, which houses two PET scanners and enables the treatment of a maximum of 5'000 patients per year (300 patients more than treated in 2016). The two PET scanners are used to diagnose two types of carcinosis. Future models of scanners may, additionally, be able to screen for Alzheimers. The likelihood of this depends on the results of ongoing Alzheimer vaccination research. As both the number of patients in the future for the two types of carcinosis and the possibility of having more patients to be treated for Alzheimers are uncertain, there is uncertainty associated with the optimal initial design of the PET centre.

The initial design has some degree of flexibility, i.e. it hosts two PET scanners to accommodate the current demand (5'000 patients), but has the additional load bearing capacity of the floor slab to add the PET/MR and the additional area necessary for expansion. It is assumed that before any change, i.e. an expansion intervention, is triggered, the hospital uses the additional space for "soft" purposes, such as administration offices, which makes it easy to expand if desired (Figure 1).

Figure 1 Floor layout with the flexible design

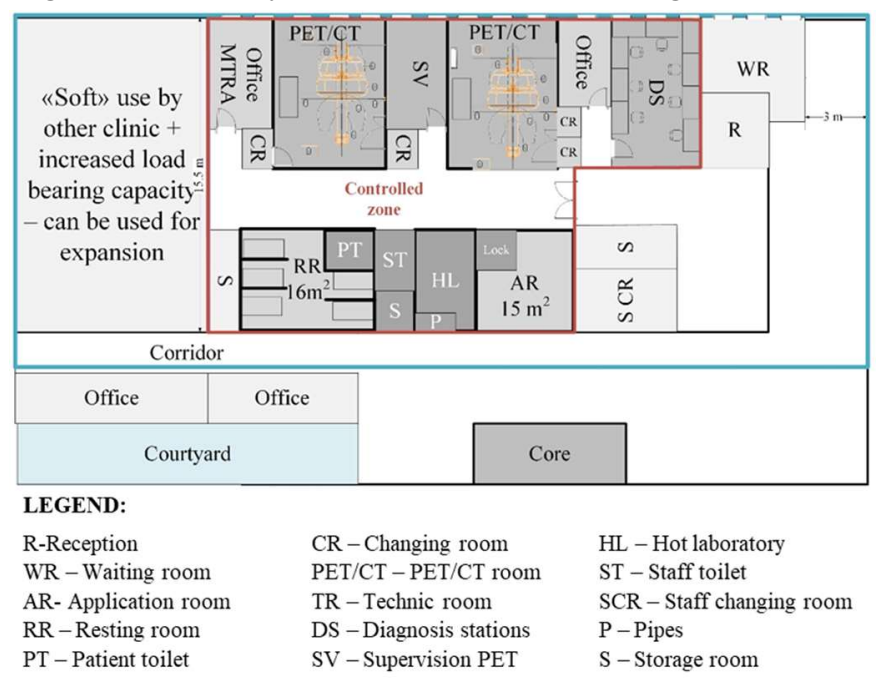

On the initial design of the floor presented in figure 1, 4 changes can be executed to expand the capability of the centre, where each is possible only when the previous has been executed, i.e. the second change is only possible after or at the same time as the first, the third only after or at the same time as the second and so on. All changes are possible only once over the investigated time-period. Possible future changes on the initial layout and their impact on the capacity of the centre are reported in table 2 .

Table 2 Possible future changes

\begin{tabular}{lll}
\hline Change & Description & $\begin{array}{l}\text { Increase } \\
\text { capacity }\end{array}$ \\
\hline 1 & purchase a PET/MR & $+2^{\prime} 500$ \\
2 & expand the application room & +500 \\
3 & expand the resting room & $+1^{\prime} 500$ \\
4 & purchase more diagnosis stations & +500 \\
\hline
\end{tabular}

\subsection{The model to evaluate the service}

The net benefits of the centre are estimated using the binomial tree method. This is done estimating the net benefitsat each node $\mathrm{n}$ of the tree at all time intervals $\left(R_{n, \tau}\right)$ as in the equation 1.

$$
R_{n, \tau}=\sum_{t=\tau+1}^{T}\left(e^{-r(t-\tau)} \sum_{n=1}^{N_{t}} \sum_{i_{n_{t}}=1}^{I_{n_{t}}}\left(q_{i_{n_{t}}} \cdot B_{i_{n_{t}}}\right)\right)
$$

Where: $\mathrm{T}$ is the investigated time period, $N_{t}$ is the number of nodes with possible values at time $\mathrm{t}, I_{n_{t}}$ is the number of possible paths leading to node $\mathrm{n}$ in at time $\mathrm{t}, q_{i_{n, t}}$ is the probability of path $i_{n_{t}}$ to node $\mathrm{n}$ at $\mathrm{t}$, and $B_{i_{n_{t}}}$ is the yearly net benefit at node $\mathrm{n}$ at $\mathrm{t}$. In the above formula the net benefit $B_{i_{n_{t}}}$ for each year $t$ is computed as in equation 2 .

$$
B_{t}=\left(P_{t, U P 1}+P_{t, U P 2} \cdot f_{\Delta P P_{t, U P 2}}\right) \cdot\left(I_{t, v}-O_{t, v}\right)-O_{t, f}-\Delta B_{t}
$$

The parameters of equation 2 are described in Table 3 .

Table 3 Possible future changes

\begin{tabular}{cl}
\hline Name & Description \\
\hline$P_{t, U P 1}$ & Patient number for existing application (UP1) \\
$P_{t, U P 2}$ & Patient number for new application (UP2) \\
$I_{t, v}$ & Income per patient \\
$O_{t, v}$ & Variable costs per patient \\
$O_{t, f}$ & $\begin{array}{l}\text { Fixed costs for the operation of the clinic } \\
\text { (independent from actual number of patients) }\end{array}$ \\
$\Delta B_{t}$ & $\begin{array}{l}\text { Additional costs for treatment of patient over } \\
\text { capacity in afternoon shifts }\end{array}$ \\
$f_{\triangle P t, U P 2}$ & $\begin{array}{l}\text { Possible reduction in patient numbers if patients } \\
\text { have to be sent to the Wagi-Areal }\end{array}$ \\
\hline
\end{tabular}


The evaluation model takes into account that the number of patients in year $t$ has not one value but follows a probability distribution according to two parameters: UP1, i.e. change in patient numbers for the existing imaging process, and UP2, i.e. the introduction of new imaging application. Hence, the expected net benefits are calculated under consideration of the probabilistic models of these two parameters, which are shortly described in the following section.

UP1 - Change in patient numbers for the existing imaging application. The UP1 is modelled as varying around 4'700 patients to consider the uncertainty on patients number evolution.

$$
\begin{gathered}
p_{t, U P 1}=\max \left(0, \min \left(1,\left(\frac{1}{2}\right.\right.\right. \\
\left.\left.\left.+\sqrt{\Delta t} \frac{k\left(\bar{P}_{\log }-P_{\log , t}\right)-1 / 2 \sigma}{2 \sigma}\right)\right)\right)
\end{gathered}
$$

With the necessary input parameters defined as in table 4.

Table 4 Parameters of Equation 3

\begin{tabular}{clll}
\hline $\begin{array}{c}\text { Input } \\
\text { parameter }\end{array}$ & Description & Unit & Value \\
\hline$\sigma$ & Variance & - & 0.1 \\
$\Delta_{t}$ & Time increment & Years & 1 \\
$k$ & Reversion factor & - & 0.3 \\
$\bar{P}_{\text {log }}$ & $\begin{array}{l}\text { Natural log of the mean } \\
\text { of the patient numbers }\end{array}$ & Patients & Log \\
& Natural log of the & & \\
& current value of the & & \\
$P_{\log , t}$ & patient numbers at an \\
& upward node in t & - \\
\hline
\end{tabular}

UP2 - Introduction of new imaging application. The demand for the pre-screening for Alzheimer's depends directly on the research success of the Alzheimer vaccination. UP 2 is modelled with a discrete lattice for a jump or Poisson process. For this lattice, the input is shown in Table 5.

\begin{tabular}{|c|c|c|}
\hline Name & Values & Description \\
\hline$P_{t, U P 2}^{+}$ & $\begin{array}{l}+2 ’ 000 \\
\text { Patients }\end{array}$ & $\begin{array}{l}\text { Additional number of patients after } \\
\text { introduction of application }\end{array}$ \\
\hline$P_{t, U P 2}^{-}$ & +0 & $\begin{array}{l}\text { Additional number of patients before } \\
\text { introduction of application }\end{array}$ \\
\hline$p_{t, U P 2}$ & 0.8 & $\begin{array}{l}\text { Probability of introduction of application } \\
\text { in the years } t=2,4,6 \text { and } 8 \text { (with the } \\
\text { probability decreasing by } 0.1 \text { in each } \\
\text { time step) }\end{array}$ \\
\hline $\begin{array}{l}1 \\
-p_{t, U P 2}\end{array}$ & 0.2 & $\begin{array}{l}\text { Probability of no introduction of } \\
\text { application in the years } t=2,4,6 \text { and } 8 \\
\text { (with the probability decreasing by } 0.1 \text { in } \\
\text { each time step) }\end{array}$ \\
\hline$\Delta_{t}$ & 2 & Time increment of change in years \\
\hline
\end{tabular}

Table 5 Input for jump process for UP 2

\subsection{Estimate of the net benefit using the ROM}

Considering the situation described in section 3.1 and the model to evaluate the service presented in section 3.2, the total net benefits at $t=0$ are estimated using the ROM, by: (a) estimating the additional net benefits for each $t$ in which it is possible to execute a change first, and then (b) estimating the net-benefit using ROM.

\section{(a) Estimate the additional net benefits for each $t$ in which it is} possible to execute a change

In order to estimate the expected net benefits of one change, it is necessary to take into consideration that other changes may be executed in the future, along with the times they will occur.

The additional net benefits of a change, $R_{n_{t}, I_{x}}^{+}$, are the differences between the expected benefits before and after a change, where the expected benefits after a change, $R_{n_{t}, I_{x}}^{+}$, are calculated according to Equation

(4), which take into consideration the variable operational costs per treated patient; the fixed operational costs; the effect of changes on the capacity thresholds; the changes in fixed costs for each change; the change costs; and the initial construction costs for different floor layouts when compared with the Basic floor layout.

$$
R_{n n_{t}, I_{x}}^{+}=R_{n n_{t+1}, I_{x}}-R_{n_{t}, I_{x}}
$$

\section{(b) Evaluate renewal projects with $R O M-A O$}

The net benefits are then estimated as $X_{t n_{t}, I_{1}}$, where the net benefits at $\mathrm{t}=0$ are the net benefits for the initial design. 


$$
\begin{aligned}
& X_{n_{t}, I_{1}}=\max \left(\sum_{i=0}^{I_{n_{t+1}}}\left(p_{n_{t+1}, i} \cdot X_{n_{t+1}, I_{1}, i}\right) ; R_{n_{t}, I_{1}}^{+}-C_{t, I 1}\right. \\
& \left.+X_{n_{t}, I 2}\right) \\
& X_{n_{t}, I 2}=\max \left(\sum_{i=0}^{I_{n_{t+1}}}\left(p_{n_{t+1}, i} \cdot X_{t n_{t+1,}, i, i}\right) ; R_{n_{t}, I_{2}}^{+}-C_{t, I 2}\right. \\
& \left.+X_{n_{t}, I 3}\right) \\
& X_{, n_{t}, I 3}=\max \left(\sum_{i=0}^{I_{n_{t+1}}}\left(p_{n_{t+1}, i} \cdot X_{n_{t+1, I 3,}}\right) ; R_{n_{t}, I 3}^{+}-C_{t, I 3}\right. \\
& \left.+X_{n_{t}, I 4}\right) \\
& X_{n_{t}, I 4}=\max \left(\sum_{i=0}^{I_{n_{t+1}}}\left(p_{n_{t+1}, i} \cdot X_{n_{t+1}, I, i}\right) ; R_{n_{t}, I 4}^{+}-C_{t, I 4}\right)
\end{aligned}
$$

\begin{tabular}{|c|c|}
\hline Name & Description \\
\hline$C_{I x}$ & Change costs for changes 1 to 4 \\
\hline$X_{n_{t}, I x}$ & $\begin{array}{l}\text { Expected net benefits of optimal decision about } \\
\text { execution of changes } 1 \text { to } 4\end{array}$ \\
\hline$I_{n_{t}, I x}$ & No. of nodes "following" node $n$ at time $t+1$ \\
\hline$p_{n_{t+1}, i}$ & $\begin{array}{l}\text { Probability of one node "following" node } n \text { at } \\
\text { time } t+1\end{array}$ \\
\hline$X_{n_{t+1}, I x, i}$ & $\begin{array}{l}\text { Expected net benefits of optimal decision about } \\
\text { execution of changes at nodes following node } \mathrm{n} \\
\text { in } \mathrm{t}+1 \text { for not executing change } I x \text { at node } \mathrm{n} \text { in } \mathrm{t}\end{array}$ \\
\hline$R_{n_{t}, I x}^{+}$ & $\begin{array}{l}\text { Additional expected net benefits from the } \\
\text { execution of changes } 1 \text { to } 4\end{array}$ \\
\hline
\end{tabular}

(6)

Where the inputs are described in table 6

Table 6: Input for Equations 5 to 8

\section{Estimate of the net benefit using the traditional method (TM)}

Opposite to the estimate done in (Esders, 2017) and reported in section 3.3 , in this section the expected net benefit at $t=0$ is estimated using the TM, i.e. without decision flexibility. This is done estimating the net benefits for a change at time $t X_{n}^{+}(t)$ with the binomial tree method, according to equation 9 .

$$
X_{n}^{+}(t)=\max \left[0 ; R_{n_{t}}^{+}-C_{t}\right]
$$

Where inputs are as in Table 7.

Table 7 Input for Equation 9

\begin{tabular}{cl}
\hline Name & Description \\
\hline$R_{n_{t}}^{+}$ & $\begin{array}{l}\text { Additional expected net benefits at node } \mathrm{n} \text { at } \\
\text { time } \mathrm{t} \text { after the execution of a change }\end{array}$ \\
$C_{t}$ & Costs for the execution of a change at $\mathrm{t}$
\end{tabular}

With the calculation of the expected net benefits $\mathrm{R}$ done as described in equation 10 . The expected net benefits from the execution of a change, $X^{+}(t)$, consider the change costs, $\mathrm{C}_{\mathrm{t}}$.

$$
X^{+}(t)=e^{-r t}\left(\sum_{n=1}^{N_{t}} R_{n_{t} I_{x}}^{+}-C_{t, I_{x}}\right)
$$

The expected net benefits of the individual change can initially be calculated independently of each other. Then, all possible combinations $\mathrm{K}$, under the consideration of the sequential execution, of all changes with the sum of all expected net benefits, $X_{t=0, I}^{+}$, from all changes, need to be determined. The combination with the maximum sum of expected net benefits is chosen as the optimal execution schedule of changes with the TM.

\section{Results and discussion}

The result of the analysis with the TM are reported in table 8 along with these obtained with the ROM (as from (Esders, 2017)) and compared in terms of probability of execution of changes and expected net benefit (ENB). 
Table 8 Comparison of the expected net benefit for the Flexible design with TM and ROM

\begin{tabular}{llllllll}
\hline Change & $\begin{array}{l}\Sigma \text { Prob. with TM } \\
{[\%]}\end{array}$ & $\begin{array}{l}\text { Year of execution } \\
\text { with TM }\end{array}$ & $\begin{array}{l}\text { ENB with } \\
\text { TM Prob. with }\end{array}$ & $\begin{array}{l}\text { ENB } \\
\text { ROM [\%] }\end{array}$ & $\begin{array}{l}\text { with } \\
\text { ROM ENB } \\
\text { TM-ROM }\end{array}$ \\
\hline Change 1 & 100 & 3 & 169.8 & 99.7 & 170.72 & -0.92 \\
Change 2 & 100 & 4 & - & 63.4 & - & - \\
Change 3 & 0 & No ex. & - & 23.8 & - & - \\
Change 4 & 0 & No ex. & - & 3.4 & - & - \\
\hline
\end{tabular}

Results show clearly how, if the building manager choses to evaluate the Flexible layout with the TM rather than with the ROM, the probabilities of execution of the changes are considered as $100 \%$, or $0 \%$, i.e. yield a fixed change program. With the ROM, instead, the probability of executing a change depends on the uncertainty modelled for the demand, i.e. the ROM yields that the decision is flexible and dependent to the demand.

The fix programs of execution of changes that derives from the evaluation with the TM allows to identify clearly the specific year of execution of changes, i.e. change 1 in year 3 and change 2 in year 4. This results in, according to the uncertainty considered on the demand, an expected net benefit of 169.8 Mil. CHF, which is 0.9 Mil. CHF less than the expected net benefits with the ROM. It is to be noticed that the small advantage gained from the ROM on the TM is due to the flexibility of decision, i.e. with ROM it is considered that under circumstances in which it is convenient to trigger the change 3 (3.4\% of the time) the building manager can do it, and when it is not desirable to trigger any change $(0.3 \%$ of the time $)$ the building manager has the freedom to avoid doing it.

It is also to be noted that the additional rigidity of defining ahead of time the year of execution of changes with the TM causes a loss of only 5\% of the estimated net benefits. This is partially due to the fact that the costs for changes 3 and 4 are quite high compared to the possible benefits and therefore the ROM recommends an execution only for very high values of the key parameters with low probability of occurrence, while the TM recommends no execution. That means that defining the year of execution of changes with the ROM exploits minor additional benefits.

\section{Conclusions}

The real world example of the PET centre of the University hospital Zurich has shown that it is possible to evaluate the expected net benefits for a flexible building using the TM without significant losses compared to the use of ROM. Indeed, even though it requires substantial less effort to estimate the net benefits with the TM rather than with the
ROM, the two methods do not generate significantly different expected net benefits.

The comparison of the expected net benefits with the TM and the ROM in this example showed that the consideration of decision flexibility (i.e. the ROM) only lead to a 0.9 Mil. CHF additional expected net benefits on the building lifetime when compared with the TM, i.e. the expected net benefits are 169.8 Mil. CHF with the TM and 170.72 Mil. CHF with the ROM.

It is concluded that, given the marginal difference in the estimated net benefits with the two methods, in this case the choice to retain or not decision flexibility in managing the building has a minor impact. Thus, for the PET centre of the University hospital of Zurich the building manager can plan changes ahead of time using the TM when needed to secure funds for changes, with nearly no losses (i.e. only $5 \%$ ) on the expected net benefits.

Because the results obtained are dependent on the input conditions of the example, it would be of interest for further works to investigate whether the expected net benefits estimated with the ROM become significantly higher than those with the TM in situations in which:

- the uncertainty of the key parameters and, as a result, the uncertainty of the expected net benefits is higher, i.e. (1) the values deviate far from the mean, which was not fully the case for the uncertain key parameter 1, and (2) the probability of occurrence is not concentrating on one scenario, which was not fully the case in this real world example for the uncertain key parameter 2, and, at the same time,

- the costs to trigger changes are lower compared to the expected net benefits from the execution of the changes. Indeed, if the costs of changes are very high, both TM and ROM would suggest not to trigger most of the time, vastly nullifying the benefit of the flexible decision process of the ROM, and

- the complexity of the example is higher. In the example treated in this article the complexity has been reduced significantly by assuming many parameters as deterministic that are in reality uncertain, such as the cost of changes. It would be of interest to note how the results 
might change between TM and ROM when a higher level of complexity is modelled.

\section{Acknowledgments}

This work was only possible through the invaluable help of $\mathrm{M}$. Wenger, R. Latour, Professor P. A. Kaufmann and T. Berthold from the University hospital Zurich and R. Ruppel from pom+ Consulting AG.

\section{References}

Ellingham, I. and Fawcett, W. (2007) New generation wholelife costing: Property and construction decision-making under uncertainty. Routledge.

Esders, M. (2017) Consideration of uncertain future demand and decision flexibility in the determination of intervention programs for buildings. ETH Zürich.

Esders, M., Adey, B. T. and Lethanh, N. (2016) 'Using real option methods as a tool to determine optimal building work programs', Structure and Infrastructure Engineering. Taylor \& Francis, 12(11), pp. 1395-1410.

Esders, M., Della Morte, N. and Adey, B. T. (2015) 'A Methodology to Ensure the Consideration of Flexibility and Robustness in the Selection of Facility Renewal Projects', International Journal of Architecture, Engineering and Construction, 4(3), pp. 126-139.

Fawcett, W. and Chadwick, A. (2007) 'Space-time management and office floorspace demand: Applied experience and mathematical simulations', Journal of Corporate Real Estate. Emerald Group Publishing Limited, 9(1), pp. 5-24.

Fawcett, W. and Rigby, D. (2009) 'The interaction of activity, space and cost variables in office workstation sharing', Journal of Corporate Real Estate. Emerald Group Publishing Limited, 11(1), pp. 38-51.

Guma A. and de Neufville, R. (2008) Real option analysis of a vertically expandable real estate development. MIT.

Martani, C. et al. (2015) 'A New Model for Evaluating the Future Options of Integrating Ground Source Heat Pumps in Building Construction', in. UCL STEaPP.

Martani, C. et al. (2016) 'Design with Uncertainty: The Role of Future Options for Infrastructure Integration', ComputerAided Civil and Infrastructure Engineering, p. n/a--n/a. doi: $10.1111 /$ mice. 12214 .

Martani, C., Cattarinussi, L. and Adey, B. T. (2018) 'A new process for the evaluation of the net-benefit of flexible ground-floor ceiling in the face of use transition uncertainty', Journal of Building Engineering. Elsevier, 15, pp. 156-170.

Menassa, C. C. (2011) 'Evaluating sustainable retrofits in existing buildings under uncertainty', Energy and Buildings. Elsevier, 43(12), pp. 3576-3583.

de Neufville, R., Lee, Y. S. and Scholtes, S. (2008) 'Using flexibility to improve value-for-money in hospital infrastructure investments', in Infrastructure Systems and Services: Building Networks for a Brighter Future (INFRA), 2008 First International Conference on, pp. 1-6. 